\title{
Educação Ambiental e Arte: Um diálogo a partir de um minicurso para formação de professores
}

Environmental Education and Art: A dialogue from a mini-course for teacher training

Educación Ambiental y Arte: Un diálogo a partir de un minicurso para la formación de profesores

\author{
Carolina de Souza Oliveira \\ Graduanda, UFLA, Brasil \\ Carolinaoliveira.s@outlook.com \\ Thales Vinícius Silva \\ Graduando, UFLA, Brasil \\ thalesvinisilva@gmail.com \\ Marina Battistetti Festozo \\ Professora Doutora, UFLA, Brasil \\ mbfestozo@hotmail.com
}




\section{INTRODUÇÃO}

A partir de um viés crítico, o ambiente possui uma dimensão histórica, social e política. Ele é um conjunto de questões determinadas pelas relações humanas assim como suas relações com o meio ambiente. Nesse sentido, a educação ambiental crítica tem como intuito promover uma educação emancipatória, em que os sujeitos sejam capazes de reconhecer o ambiente em que vivem, suas problemáticas sociais, culturais e políticas e o contexto histórico em que estão inseridos para que assim possam agir no sentido de transformá-lo (MEYER, 1992).

Uma visão dialética entende que homem e natureza formam uma mesma unidade, sendo o homem uma extensão dela. Assim, para que essa educação emancipatória aconteça, é importante que os sujeitos se reconheçam como parte da natureza, e não como isolados a ela (TOZONI-REIS, 2004).

No entanto, em oposição a essa visão, historicamente o homem tem construído sua relação com a natureza baseada na degradação e na exploração. De acordo com Trein (2012), a relação histórica construída pelo homem com a natureza de modo a explorá-la visando de forma pontual seu benefício próprio, possibilitou uma visão de que o ser humano é cada vez menos natureza e cada vez mais cultura.

Objetiva-se uma educação em que o sujeito além de se reconhecer como parte do meio também seja capaz de perceber sua realidade de forma crítica. Buscam-se então metodologias para que o objetivo da educação ambiental possa ser alcançado, considerando o envolvimento dos participantes nesse processo de construção de conhecimentos (SATTO, 2002).

Nesse sentido, a arte pode proporcionar essa compreensão uma vez que ela é uma manifestação humana que revela questões do ambiente em que estão inseridos os artistas, sendo muitas vezes em forma de protestos e críticas a esse ambiente. Aprender a ler obras de arte é um estímulo para que se aprenda a ler a própria realidade (BARBOSA, 1989).

Além disso, a arte ainda pode se manifestar a partir de diversas linguagens como pinturas, esculturas, desenhos, músicas e poesias, o que a enriquece e abrange uma grande quantidade de formas diferentes de percepções.

A arte e a ciência se complementam para uma interpretação holística da realidade. Por um lado, os conhecimentos científicos abordam a razão e por outro, a arte aborda os sentimentos. Ambos são resultados de ação humana e, portanto, da forma como o homem se coloca no mundo (NASCIMENTO JÚNIOR, 2009).

Considerando a importância da educação ambiental e o potencial da arte como forma de proporcionar uma leitura mais completa da realidade, foi construído um minicurso com o tema "Educação Ambiental e Arte", como parte do "I Conferência de Formação de Professores", realizado na Universidade Federal de Lavras, em 2017.

Nesse sentido, o presente trabalho objetiva relatar e discutir as experiências e as reflexões proporcionadas por essa atividade dentro da perspectiva da formação de professores. 


\section{METODOLOGIA}

\subsection{Desenvolvimento do Minicurso}

O minicurso aconteceu na "I Conferência de Formação de Professores", realizado na Universidade Federal de Lavras, MG, em 2017. Inicialmente, para sua preparação, os prelecionistas visitaram alguns bairros da cidade com o intuito de observar o entorno da Universidade e fotografar problemas ambientais encontrados nele. As fotos tiradas foram editadas com montagens a fim de problematiza-las e causar discussões. Essas imagens juntamente com charges retiradas do livro "Só dói quando eu respiro", de Caulos, foram dispostas nas paredes da sala onde o minicurso foi realizado.

A atividade do minicurso se iniciou com a apresentação de uma tartaruga e de uma cesta feitas de folha de palmeira, assim como a escultura de uma mulher feita a partir de barro. Em seguida, os participantes foram convidados a criarem em conjunto uma história para a tartaruga e outra para a mulher. A criação dessas histórias possibilitou discussões acerca de diversos temas relacionados à educação ambiental.

Em determinado momento, a discussão a partir da escultura de barro abordou o tema da construção de barragens. Assim, os prelecionistas apresentaram um poema encenado chamado "A indignação de uma mulher", retirado do site do Movimento dos Atingidos por Barragens (MAB), em que à medida que iam declamando o poema, os prelecionistas se sujavam de barro durante a apresentação.

Posteriormente a essas discussões iniciais, partiu-se para a segunda etapa do minicurso. Nela, os participantes foram convidados a observar as imagens e as charges dispostas nas paredes e retirarem aquelas que mais Ihes chamasse atenção. Em seguida, cada participante compartilhou com o grupo as imagens escolhidas e o motivo de terem chamado atenção deles. Assim, diversas questões como exploração do trabalho, alienação e a questão do lixo foram discutidas em conjunto.

\subsection{Forma de análise}

Para fins de análise, as questões discutidas durante o minicurso foram pontuadas a partir das potencialidades que os recursos utilizados (imagens, esculturas e poesia) possuem para a discussão da Educação Ambiental e formação de professores.

\section{RESULTADOS E DISCUSSÃO}

\subsection{A tartaruga de folhas de palmeira}

Inicialmente, os participantes construíram uma história para a tartaruga feita de folhas de palmeira. Denominada Joana e vinda de Pernambuco, onde vivia e se reproduzia, ela teria chegado até aqui vítima do tráfico de animais. A partir disso, a primeira discussão foi acerca da questão do contrabando de animais no Brasil.

Posteriormente, também a partir da história, surgiram questões sobre a condição dos mares. Foi discutido que a poluição nestes é causada majoritariamente por indústrias que despejam 


\section{Periódica Eletranica

grandes quantidades de resíduos sem levar em conta os ecossistemas que são afetados com isso.

Assim, foi observado pelos participantes que, na maior parte das vezes, nos meios midiáticos há uma culpabilização da população pela poluição e degradação ambiental e uma isenção da responsabilidade das grandes empresas, que são as maiores causadoras da degradação dos rios, mares, florestas e seus componentes.

Também foi observado pelos participantes que o mesmo acontece relacionado à educação ambiental tratada na maior parte das escolas. No geral, trata-se de conscientização individual em que cada um deve cuidar do seu lixo e cuidar para não desperdiçar água, mas não traz uma reflexão crítica acerca dessas questões. Loureiro, 2008, discute as diferentes visões relacionadas à Educação Ambiental nas escolas. Segundo ele, a questão ambiental foi inserida no Brasil na época da ditatura por pressão exterior. Havia uma grande influencia da visão conservacionista proveniente da classe média europeia. Assim, a ideia de ambiente era fragmentada e descolada da realidade. Nesse sentido, a educação conservacionista entendia a natureza como harmônica e os seres humanos com papel de se adequar a ela a partir da mudança de hábitos culturais e individuais (LOUREIRO, 2008).

Há documentos referências para a política, economia e educação. A Agenda 21, pactuada pelos países na Rio-92, trata a relação ambiental baseada na sustentabilidade objetivando o crescimento econômico dos países. Segundo Cruz (2014), a implantação da Agenda 21 nas escolas públicas de São Paulo ocorreu de maneira descontínua e fragmentada, sob uma perspectiva neoliberal.

Por outro lado, o Tratado da Educação Ambiental para Sociedades Sustentáveis e Responsabilidade Global de 1992 (FÓRUM INTERNACIONAL DAS ONGs, 1995) trata a questão da sustentabilidade a partir de uma visão mais crítica e transformadora, abordando uma crítica ao sistema econômico capitalista de países desenvolvidos, buscando o entendimento da sociedade e a participação coletiva em decisões políticas (JANKE, 2012).

A institucionalização da Educação Ambiental aconteceu no Brasil nos anos noventa. Em 1992 foi criado o Ministério do Meio Ambiente e foram instituídos Núcleos de Educação Ambiental. A partir de 1997 a educação ambiental foi colocada como um dos temas transversais nos Parâmetros Curriculares Nacionais (PCN), sendo um importante marco para sua inserção nas escolas.

Desse modo, é possível perceber como a abordagem da educação ambiental é resultante de um processo histórico, influenciado por acontecimentos políticos e econômicos. Apesar de o tema ter sido iniciado com o movimento ambientalista, com um viés conservador, essa perspectiva está se alterando ao longo da história.

Posteriormente foram observados os aspectos artísticos da tartaruga e o olhar do artista comparando-a a cesta do mesmo material que também estava disposta durante a atividade.

Foi discutido sobre como a partir do mesmo material, no caso as folhas de palmeira, o artista produziu dois objetivos diferentes.

Numa perspectiva de construção de uma educação crítica transformadora, segundo Saviani (2008), há o enfrentamento das contradições sociais a partir da compreensão da realidade de maneira holística assim como de suas características marcadas pela exploração. A arte pode auxiliar nessa compreensão da realidade. Em toda obra, seja ela de cinema, literatura, pintura, 
dança há um pensamento sobre da condição humana, e assim, nos leva a uma perspectiva estética da existência (MORIN, 2003).

Segundo Antônio Damásio (apud GALVÃO, 2006) "um currículo escolar que integra as artes e as humanidades é imprescindível à formação de bons cidadãos". Assim, compreende-se o potencial de se utilizar a arte no ambiente educacional com propósito de recuperar o passado, compreender o presente, articular os diferentes âmbitos e estimular a criatividade e a criticidade.

\subsection{A escultura de barro e o Poema}

A mesma dinâmica de construção de uma história em conjunto aconteceu com a escultura de barro da mulher. O nome dado a ela foi Josefina e ela veio do norte de Minas Gerais. Ela tinha um pai, seu criador, que seria um artesão daquela região. A partir disso, foi discutido como o barro pode ser utilizado para produzir objetos de arte e como é feito esse processo.

A partir do barro foi abordada a ideia de que este também poderia ter efeito negativo em desastres ambientais. Então surgiu o tema do desastre do rompimento da barragem de Mariana, ocorrido em 2015. Assim, foi apresentado o poema "A indignação de uma mulher", retirado do site do $M A B$. Ele retrata a indignação de uma mulher cuja família foi atingida pela construção de uma barragem próxima a casa deles e que, apesar disso, não têm acesso à energia, além de dificuldades para se alimentar. A mulher aborda a opressão que é a base do sistema capitalista e sua vontade de mudar a situação.

A mídia tida hoje em dia apresenta a informação já pronta, mastigada, e isso gera alienação a notícia, o sujeito deixa de pensar e refletir sobre esta, descartando-a da mesma forma que recebeu. Os veículos midiáticos influenciam de maneira significante a sociedade, especialmente os jovens, já que a mídia pode se manifestar de diversas formas, influenciando como a informação chega às pessoas, sendo muitas vezes manipuladas para que as interpretações sejam de acordo com os interesses (DINIZ, 2012).

Assim, é importante que a questão da mídia seja discutida nas escolas para que os alunos tenham uma formação crítica, minimizando as chances de manipulação pelos veículos midiáticos, que segundo McLuhan (1968), são agentes "produtores de acontecimentos", e não agentes "produtores de consciência".

A linguagem poética foi escolhida para a discussão desses assuntos por ser capaz de tocar o ser humano de uma maneira mais profunda, transferindo o sentimento de quem sentiu na pele $o$ impacto da barragem. A poesia tem o potencial de agir no sujeito de forma que abra sua perspectiva para caminhos que antes estavam fechados, como mostrado por Lopez (2007), a linguagem poética tem a capacidade de atingir o sujeito e faze-lo refletir ampliando seus horizontes pessoais, transcendendo qualquer suposição de um conhecimento absoluto.

A partir do poema foi discutido como os desastres como construção de hidrelétricas e a mineração causam efeitos negativos na vida da população que vive ao redor. Foram permeados assuntos de políticas públicas e como isso afeta a comunidade e o meio ambiente diretamente.

Em seu trabalho, Trein (2012) faz uma crítica ao sistema capitalista de produção que é dependente da relação predatória e de exploração com o solo e com a água, causando danos ambientais e sociais. 
$\mathrm{Na}$ segunda etapa do minicurso os participantes observaram as imagens dispostas e escolheram algumas que os chamaram atenção. Essas imagens foram levadas para discussão em roda, onde cada um compartilhou com o grupo sua imagem e os motivos que levaram a escolha delas.

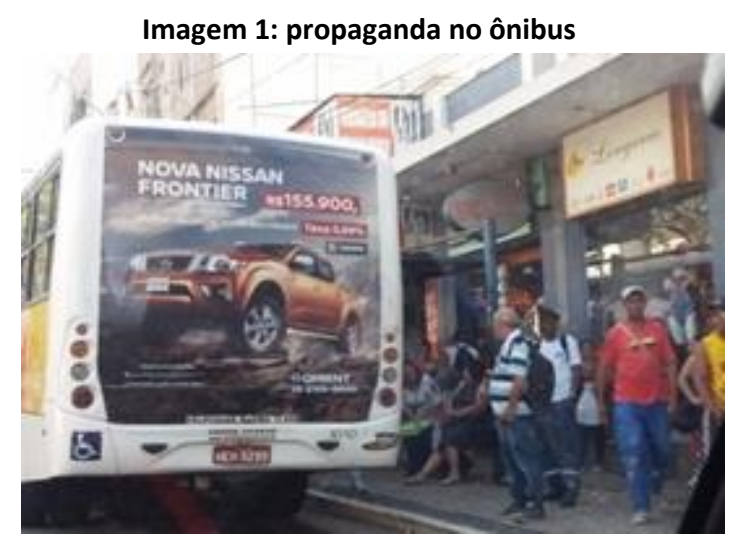

Fonte: AUTORES, 2018.

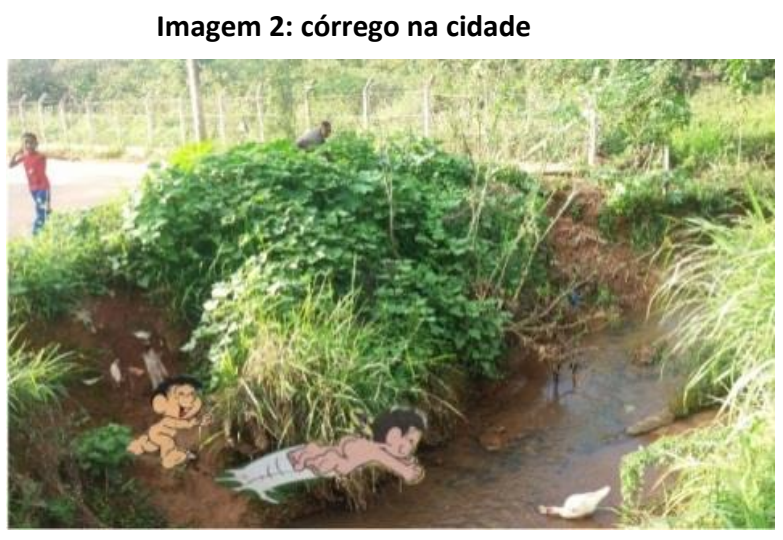

Fonte: AUTORES, 2018.
Imagem 3: Alienação no trabalho

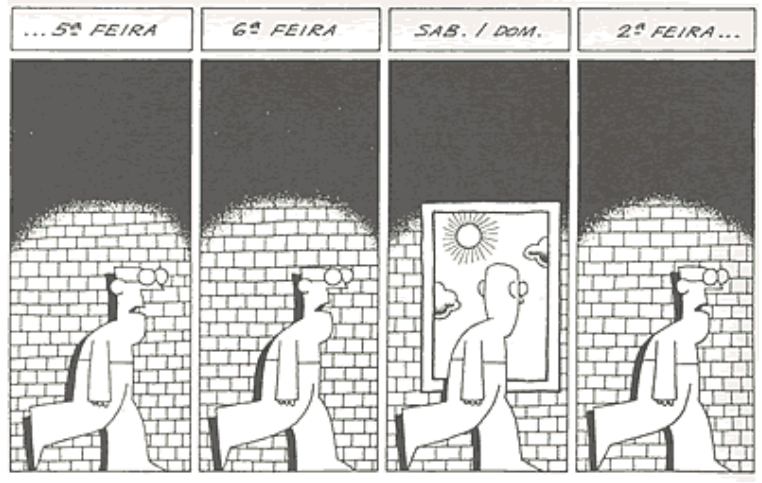

Fonte: CAULOS, 2001.

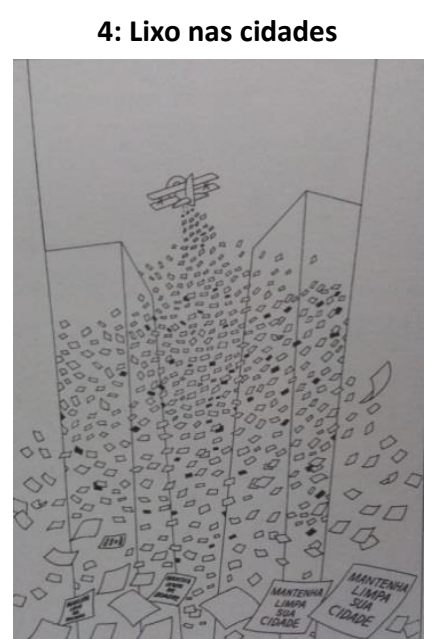

Fonte: CAULOS, 2001. 
Imagem 5: Boneca de barro

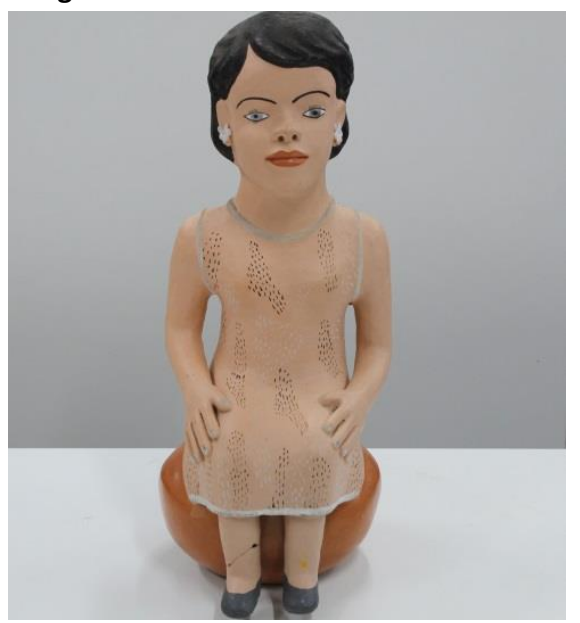

Fonte: AUTORES, 2018.

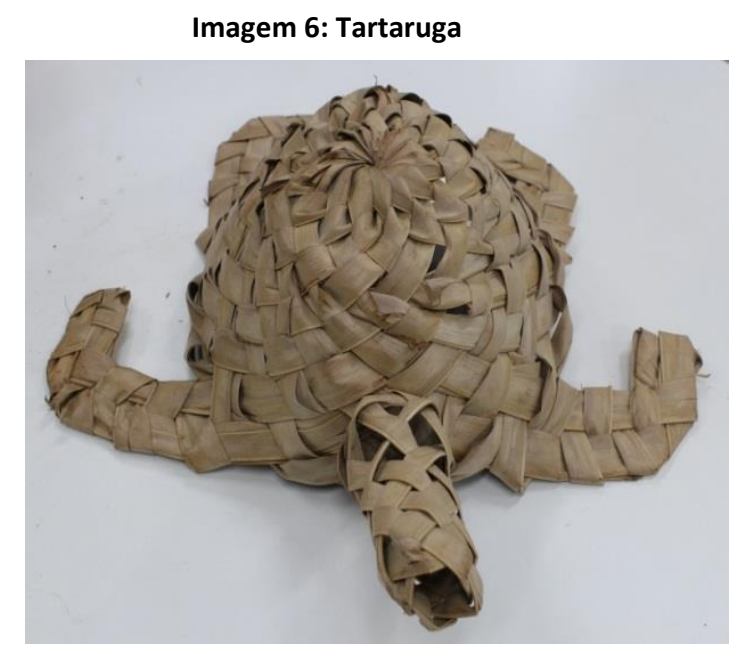

Fonte: AUTORES, 2018.

\subsection{As montagens}

Arte é tudo aquilo que prende a atenção de alguém e a faça ter, ao menos por um instante, um momento de reflexão, contemplação da obra. Utilizar-se então da arte para se trabalhar a educação ambiental acarreta na formação do sujeito em duas perspectivas, uma formação sobre cidadania e garantindo uma visão crítica da sociedade e ambiente ao qual faz parte, e uma formação artística, uma vez que em contato com obras artísticas o sujeito tem a oportunidade expandir seus olhares sobre a vida e o mundo, culminando por incorporar as estruturas mais intrínsecas da concepção, da reflexão e do caráter do ser. (OLIVEIRA, 2003)

A arte muda o tempo todo e hoje pode ser representada até por meio de montagens feitas em programas de computador. Utilizamos então de um desses juntamente com fotografias retiradas na cidade para mostrar um cotidiano que muitas vezes passa despercebido aos olhos dos cidadãos. As fotos foram capturadas em um dia comum da cidade justamente para discussão no minicurso e a algumas das colagens feitas utilizam de personagens conhecidos da televisão interagindo com o ambiente. Apenas uma das fotos não precisou ser alternada, é o caso da primeira imagem.

Do mesmo modo que alguns veículos de mídia apontam o fato do tráfico de carros estarem aumentando e com isso o caos provocado no trânsito estar crescendo mais e mais, a mídia particular, ou seja, a propaganda que visa garantir lucro a alguma instituição ou pessoa, direciona seus espectadores para a venda de produtos, como é o caso da nova super caminhonete da Nissan. Nessa foto podemos observar a propaganda de um automóvel na traseira de um ônibus metropolitano. $O$ interessante da imagem são as pessoas ao lado no ponto de ônibus, aguardando a passagem deste ou do próximo transporte. $O$ automóvel custa em torno de 155 mil reais, a tarifa do ônibus em questão custa três reais e cinquenta centavos. A diferença do preço é exorbitante, porém a relação entre as pessoas que estão esperando o ônibus na foto e o público que essa propaganda visa atingir é mais distante ainda. A realidade de um cidadão que necessita de um transporte público que o leve para determinado local pagando uma quantia por viagem é bem diferente da realidade de quem tem condição de ter e 
sustentar um veículo de tamanho custo. Porém, essas duas realidades se chocam no momento que a propaganda está presente na realidade daquelas pessoas, mas distante de sua realidade econômica. Essas e outras discussões surgiram a partir da reflexão dos participantes e dos prelecionistas quando se puseram a admirar e refletir sobre a obra.

Outra obra bem interessante é a segunda imagem que mostra a realidade de um córrego que passa dentro de um bairro pobre da cidade. Próximo ao córrego havia uma casa com algumas crianças brincando em frente a ela. Em conversa com as crianças, foram questionadas se costumavam brincar ou ter algum tipo de contato com aquele córrego. Elas disseram que isso não acontecia. No entanto, passado algum tempo naquele local conhecendo e escolhendo as melhores composições para as fotos, as crianças começaram a brincar no seu entorno e inclusive participaram do processo de escolher os melhores locais para as fotos.

A partir disso é possível notar como o entorno das casas fazem parte da vida das pessoas, que muitas vezes se acostumam com determinadas situações e não são incentivadas a transformálas. O córrego tinha sinais de poluição com lixo jogado nele. Um córrego poluído e contaminado pode causar problemas de saúde pública, causando danos para as pessoas da região que tem algum tipo de contato com ele.

Assim como essas apontadas, as demais montagens trouxeram importantes reflexões como questões relacionadas ao lixo nas cidades, à distribuição desigual de renda e à alienação no trabalho.

Para enriquecer a discussão, as montagens foram relacionadas com charges que também abordavam essas questões. Como exemplo, a terceira imagem aborda a questão da alienação do trabalho. O personagem passa toda a semana dentro de um ambiente fechado, com as paredes de tijolos, representando seu local de trabalho e aos finais de semana ele pode ver o sol através de uma janela. Representa a superficialidade das relações humanas e do contato com a natureza, além de um trabalho em que o homem não vê sentido no que faz.

A questão do trabalho é abordada pela autora Trein (2012), que discute como o trabalho se transformou em apenas produção de bens materiais visando o lucro, deixando de lado seu potencial de transformação do homem, de produção artística e cultural. Assim, o trabalho no modelo econômico capitalista tem característica de alienação e mercantilização.

Ainda, a quarta imagem traz uma discussão acerca da poluição nas cidades. Nela, há um avião jogando folhetos de papel por toda cidade com a mensagem "mantenha a cidade limpa". Representa como grandes empresas se preocupam em divulgar um trabalho ecologicamente correto, quando na verdade o que fazem são trabalhos pontuais, que mascaram problemas ambientais e não atuam realmente de forma a diminuir as relações de exploração, uma vez que o lucro é objetivado a qualquer custo seguindo um modelo de sistema capitalista. Ainda, traz uma culpabilização da população em relação à poluição e às questões ambientais de forma geral.

O processo de tirar as fotografias conhecendo o entorno da cidade, refletir sobre elas para criar as montagens e posteriormente discuti-las em um minicurso foi um processo rico que trouxe importantes questões para a formação de professores. 


\section{CONSIDERAÇÕES FINAIS}

Trabalhar a formação de professores acarreta em alterar, agregar e melhorar a sua atuação prática, construir espaços de formação onde estes são expostos a novas metodologias de ensino e novas perspectivas são fundamentais para que haja uma mudança significativa na educação da nossa sociedade. $\mathrm{O}$ ambiente em que estamos inseridos sofre mudanças e a formação de professores tem que mudar junto, a caminho da melhoria do nosso sistema de ensino.

A educação ambiental crítica é capaz de abrir novos caminhos para essas mudanças. Discutir desde cedo questões ambientais estruturantes da nossa sociedade faz com quem os alunos possam crescer e entender o mundo com uma visão mais ampla e contextualizada da realidade e a conjuntura em que estão inseridos, formando assim cidadãos conscientes, críticos e autônomos.

Podemos observar que a arte, em todas as suas vertentes, é um importante veículo dessa mudança. Ela é capaz de abranger discussões e reflexões que podem ser realizadas exclusivamente a partir dela. Entender então seu papel e utilizar do olhar artístico na educação de jovens e adultos se mostra muito significativo e prazeroso.

Assim, é possível concluir a importância dos sujeitos conhecerem o meio em que estão inseridos, identificar as problemáticas ambientais, discuti-las e relacioná-las a fim de buscar transformações. Esse processo pode se dar por meio da arte, que proporciona uma leitura do mundo, assim como é uma maneira de se expressar diante dele. Dessa forma, entende-se a contribuição da arte para trabalhar educação ambiental e sua importância na formação de professores e na formação emancipatória.

\section{REFERÊNCIAS BIBLIOGRÁFICAS}

BARBOSA, Ana. Mae. Arte-Educação no Brasil: realidade hoje e expectativas futuras. Estudos avançados, v. 3, n. 7, p. 170-182, 1989.

BUCHALA, SIMONE AZEVEDO; OLIVEIRA, EDILSON MOREIRA. A arte como princípio articulador da Educação Ambiental. In: Seminário Internacional de Educação, 2004, São Paulo. Seminário Internacional de Educação/UNINOVE-SP. São Paulo: UNINOVE, 2003.

CAULOS. Só dói quando e respiro. Porto Alegre: L\&PM, 2001.

CRUZ, Cruz, Lilian Giacomini. Políticas Públicas de Educação Ambiental: um estudo sobre a Agenda 21 escolar. Tese (Doutorado) UNESP, Faculdade de Ciências, Programa de Pós-Graduação em Educação para a Ciência, Bauru, 2014.

DOS SANTOS DINIZ, Irlla Karla; DE ANDRADE RODRIGUES, Heitor; DARIDO, Suraya Cristina. Os usos da mídia em aulas de Educação Física escolar: possibilidades e dificuldades. Movimento, v. 18, n. 3, 2012.

GALVÃO, Cecília. Ciência na literatura e literatura na ciência. Interações, Lisboa, n. 2, v. 3, p. 32-51, 2006.

FORUM INTERNACIONAL DAS ONGs. Tratado de educação ambiental para sociedades sustentáveis e responsabilidade global. Rio de Janeiro: 1995.

JANKE, Nadja. Política Nacional de Educação Ambiental: contradições e disputas. Tese (Doutorado em Educação Para a Ciência). Programa de Pós-Graduação em Educação Para Ciência. Faculdade de Ciências. UNESP - Bauru, 2012. 


\section{sur orum Ambiental \\ da Alta Paulista}

Volume 14, Número 5, 2018

ISSN 1980-0827

LOPES, Anchyses Jobim. Psicanálise, poesia e educação: a imagem furo e a leitura poética. Estudos de psicanálise, $n$. 30, p. 17-27, 2007.

MEYER, Mônica Angelo. Ecologia faz parte do espaço cotidiano. Revista AMAE EDUCANDO, Belo Horizonte, n. 225, março de 1992 (13-20).

MORIN, Edgar. A cabeça bem feita: repensar a reforma, reformar o pensamento. Rio de Janeiro: Bertrand Brasil, 2003.

MCLUHAN, Marshall. Revolução na comunicação. Rio de Janeiro: Zahar Editores, 1968. Os meios de comunicação como extensões do homem. São Paulo: Cultrix, 1969.

NASCIMENTO JÚNIOR, Antonio Fernandes; DE SOUZA, Daniele Cristina. Fazer artístico na popularização do conhecimento biológico: relato de experiências I. REMEA-Revista Eletrônica do Mestrado em Educação Ambiental, v.23, 2009.

TREIN, Eunice Schilling. A Educação Ambiental Crítica: crítica de quê? Revista Contemporânea de Educação, vol. 7, n. 14, agosto/dezembro de 2012.

TOZONI-REIS, Marília Freitas Campos. Educação Ambiental: natureza, história e razão - Campinas, SP. Autores associados, 2004. (Coleção educação contemporânea).

SATO, Michele. Educação ambiental. São Carlos, Rima, 2002.

SAVIANI, Dermeval. Escola e Democracia. Campinas: Autores Associados, 2008.

APOIO: CAPES E FAPEMIG 